\title{
Chitosan Extraction from Goliathus orientalis Moser, 1909: Characterization and Comparison with Commercially Available Chitosan
}

\author{
Pauline Fournier ${ }^{1,2}$, Caroline R. Szczepanski ${ }^{3}{ }^{(\mathbb{D}}$, René-Paul Godeau ${ }^{1,2}$ and \\ Guilhem Godeau 1,2,*iD \\ 1 Institut de Physique de Nice (INPHYNI), Université Côte d'Azur, UMR 7010, 06000 Nice, France; \\ pauline.fourniernice@gmail.com (P.F.); rp.godeau@club-internet.fr (R.-P.G.) \\ 2 Institut Méditerranéen du Risque de l'Environnement et du Développement Durable (IMREDD), \\ Université Côte d'Azur, 06200 Nice, France \\ 3 Department of Chemical Engineering \& Materials Science, Michigan State University, East Lansing, \\ MI 48824, USA; szcz@msu.edu \\ * Correspondence: guilhem.godeau@univ-cotedazur.fr; Tel.: +33-489-152-904
}

Received: 28 February 2020; Accepted: 23 April 2020; Published: 26 April 2020

\begin{abstract}
Chitosan is a polymer obtained by deacetylation of chitin, and chitin is one of the major components of the arthropod cuticle. Chitin and chitosan are both polysaccharides and are considered to be an interesting class of biosourced materials. This is evident as chitosan has already demonstrated utility in various applications in both industrial and biomedical domains. In the present work, we study the possibility to extract chitin and prepare chitosan from the Goliath beetle Goliathus orientalis Moser. The presented work includes description of this process and observation of the macroscopic and microscopic variations that occur in the specimen during the treatment. The prepared chitosan is characterized and compared with commercially available chitosan using infrared and thermogravimetric analysis. The deacetylation degree of prepared chitosan is also evaluated and compared with commercially available shrimp chitosan.
\end{abstract}

Keywords: goliath beetle; biopolymer extraction; chitin; chitosan

\section{Introduction}

Chitin, along with cellulose, is one of the most abundant biopolymers present in nature. Chitin is a major constituent of the Arthropoda's shield as well as the cell wall of fungi. Furthermore, chitin is produced on a massive scale from the waste associated with processing of seafood products such as crab and shrimp [1-5]. Chemically speaking, chitin can be described as a linear polymer (polysaccharide) of $\beta-1,4$ linked $N$-acetylglucosamine, and different sub-types of chitin are described in the literature, including $\alpha, \beta$ and $\gamma$. These sub-types are determined by the organization of the polysaccharide fibres (e.g., parallel or anti-parallel). In Arthropoda's exoskeleton, the most abundant form of chitin is the $\alpha$ form [6], which has increased stability due to a fully anti-parallel organization that leads to strong hydrogen interactions [7]. As a chemical, $\alpha$-chitin is difficult to use, due to its poor solubility in most common, organic solvents, which results from strong intermolecular interactions and a compact macromolecular structure. Typically, to avoid this solubility limitation, chitin is modified prior to industrial use. The modified version of chitin that is more frequently employed is partially deacetylated; if this modification results in a high deacetylation degree (e.g., greater than $50 \%$ deacetylation) the material is typically referred to as chitosan. [8] Due to the free amine groups released during deacetylation, chitosan has a completely different solubility compared to chitin. As one example, chitosan is fully soluble in acidic water (whereas chitin is insoluble). Due to these favourable 
properties—biocompatibility, improved solubility, and biodegradability—chitosan has a wide range of applications in food, medical, and textile applications, as reported in reviews [9-16].

Among the various uses of chitosan, biologically related applications are of special relevance and currently a growing area of research. Chitosan is used in tissue engineering, the development of injectable hydrogels and wound healing as well as for implant materials [17-22]. In acidic conditions, chitosan has a positively charged structure. This characteristic causes chitosan to strongly interact with negatively charged entities including biomolecules such as lipids, proteins and nucleic acid derivatives. These interactions make chitosan very attractive for biomimetic drug delivery and biological applications [23-25]. Another growing area of applications for chitosan is in the food packaging industry. As an example, chitosan is often explored for the development of antibacterial packaging films that can avoid bacterial growth and/or kill microorganisms [26-28]. Beyond these more biologically focused applications, chitosan is also explored for metal complexion for catalysis or depollution, demonstrating the broad interests and uses of this molecule [29-31].

Chitosan's solubility and other properties are strongly correlated with deacetylation degree, and, depending on the species used for chitin extraction, this degree can vary dramatically. As an example, Marei et al. reported deacetylation degrees of chitosan from various species: $74 \%$ for shrimp, $98 \%$ for locust, $96 \%$ for honeybee and $95 \%$ for beetle [32]. For industrial production and use, the majority of chitin is sourced from seafood waste (e.g., shrimp, crab, and lobster) but alternative chitin sources such as coral and fungus have also been reported [33-36] In the literature, various insects have also been investigated for chitin extraction and chitosan preparation, including beetles of various sizes, larvae, and adults [37-41], and, therefore, beetle cuticles may be considered a valuable source of chitin and chitosan for future industrial production. Beetles have long been considered a potential source of protein to feed humanity, since insect proteins are of good quality and their production requires minimal space and water, and also produces fewer greenhouse gases compared to production of classical animal proteins [42,43]. However, similar to seafood, large scale beetle consumption will produce waste [44], and, just as for shrimp, lobster and crab, the waste from beetle protein production will require treatment. One possibility to create value from such industrial waste is to extract chitin and chitosan. In this work, we investigate the possibility to use large-bodied beetles as specimens of interest for chitin extraction and chitosan preparation.

Recently, our work has focused on the application of beetles as inspiration for materials science, with an emphasis on surface properties of beetle shells [45,46]. As one example, in a prior study we investigated the surface properties of G. orientalis Moser [47] and observed variations in surface wettability depending on the local coloration (white vs. black). In the present work, we shift our focus to the possibility of extracting chitin and preparing chitosan from G. orientalis Moser. Chitosan is obtained following a demineralization/deproteination/deacetylation strategy (Figure 1), and the products from this process are investigated and compared to commercially available shrimp chitosan using infrared and thermogravimetric analysis. For all modification steps, the G. orientalis exoskeletons were observed for macroscopic and microscopic morphologies. These observations highlight an interesting macroscopic evolution during the treatment, revealing hidden G. orientalis iridescence. This work confirms the possible use of G. orientalis as potential starting material for chitin extraction and chitosan preparation. 


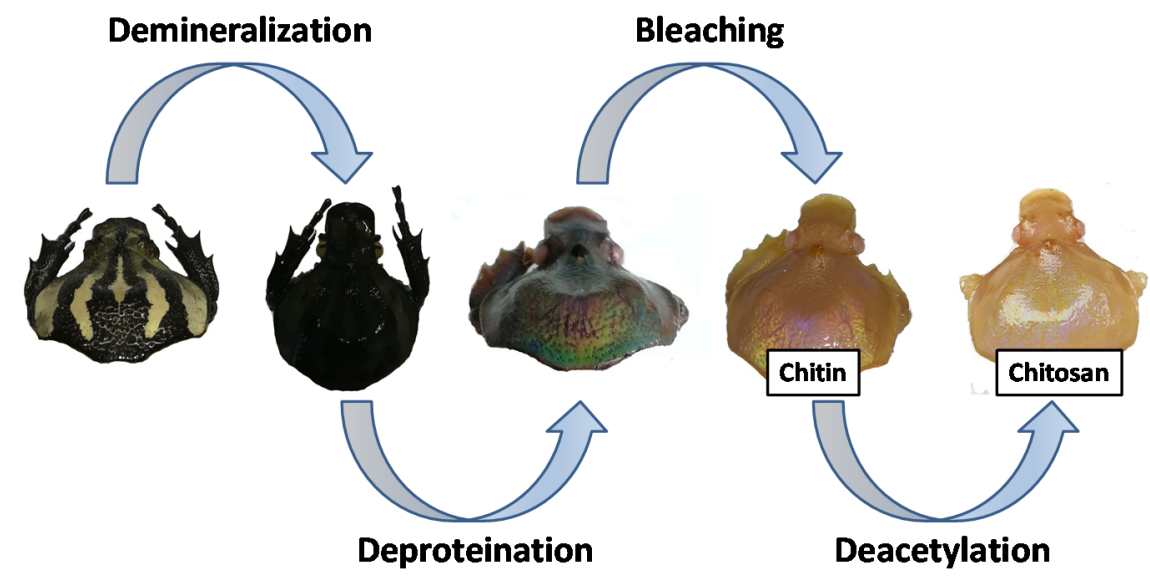

Figure 1. General concept for chitosan preparation from G. orientalis.

\section{Materials and Methods}

Specimens were acquired in a dead and dry state from a laboratory stock collection. All chemicals and solvent employed in this study were purchased from Sigma-Aldrich and used without further purification.

\subsection{Chitin Extraction}

Step 1, demineralization: dry G. orientalis (10.5 g) was hydrated in an aqueous $1 \mathrm{M} \mathrm{HCl}$ solution. The solution was then warmed for $2 \mathrm{~h}\left(95^{\circ} \mathrm{C}\right)$. The liquid phase was then removed and G. orientalis was rinsed with water until reaching a neutral $\mathrm{pH}$. The demineralized G. orientalis was directly used for the next step without further purification or drying.

Step 2, deproteination: after step 1, the resulting exoskeleton was placed in an aqueous $2 \mathrm{M} \mathrm{NaOH}$ solution. The solution was then warmed to $95{ }^{\circ} \mathrm{C}$ and held at this temperature for $36 \mathrm{~h}$. During this period, the solution rapidly transitioned to a black colour. The $\mathrm{NaOH}$ solution was refreshed every hour until the solution maintained a clear brown appearance. The liquid phase was then removed and the $G$. orientalis specimen was rinsed with fresh water until reaching a neutral $\mathrm{pH}$. The G. orientalis specimen was directly used for the next step without further purification or drying.

Step 3, bleaching: lastly, the exoskeleton was bleached using an aqueous $\mathrm{H}_{2} \mathrm{O}_{2}$ solution $(50 \% \mathrm{w} / \mathrm{w})$ at room temperature for $4 \mathrm{~h}$. The G. orientalis was then washed with water and acetone. The treated G. orientalis was dried in oven $\left(60^{\circ} \mathrm{C}\right)$, yielding $1.7 \mathrm{~g}$ of Chitin (yield $16 \%$ ).

\subsection{Chitin Deacetylation (Chitosan Preparation)}

One gram of dry chitin was rehydrated in a $50 \%(w / w) ~ N a O H$ water solution. The solution was then warmed $\left(95^{\circ} \mathrm{C}\right)$ overnight. The liquid phase was removed and the solid was washed with fresh water until reaching a neutral $\mathrm{pH}$. The deacetylated chitin (chitosan) was then washed with acetone and dried in an oven $\left(60^{\circ} \mathrm{C}\right)$, yielding $0.8 \mathrm{~g}$ (yield: $80 \%$ ) of chitosan.

\subsection{Surface Characterization}

All surface characterizations were performed on both G. orientalis and commercially available shrimp chitosan. All observations were performed 3 times to obtain standard deviation.

\subsubsection{Electronic Microscopy}

SEM observations were carried out using Phenom ProX scanning electron microscope. Samples were observed with gold coating at an accelerating voltage of 5 and $10 \mathrm{kV}$. The samples were coated using Q150R S Sp. 


\subsubsection{Infrared Measurement}

Infrared measurements were carried out using a Spectrum Two FT-IR spectrometer from Perkin Elmer with a universal ATR accessory. The measurements were performed between $4000 \mathrm{~cm}^{-1}$ and $500 \mathrm{~cm}^{-1}$.

\subsubsection{Determination of the Deacetylation Degree of the Chitosan}

Dried chitosan $(0.1 \mathrm{~g})$ was dissolved in $30 \mathrm{~mL}$ of $0.1 \mathrm{M} \mathrm{HCl}$ acid. When chitosan was completely dissolved, the solution was titrated with a $0.1 \mathrm{M} \mathrm{NaOH}$ solution.

Deacetylation degree of chitosan $[48,49]$ was calculated using the following formula:

$$
\text { Deacetylation degree }(\%)=2.03 \times \frac{V 2-V 1}{m+0.0042 *(V 2-V 1)}
$$

where $\mathrm{m}$ is sample mass $(\mathrm{g}), \mathrm{V} 1$ and $\mathrm{V} 2$ are volumes of $\mathrm{NaOH}$ solution corresponding to the deflection points for $\mathrm{HCl}$ and chitosan hydrochloride, respectively, 2.03 is a coefficient resulting from the molecular weight of the chitin monomer unit and 0.0042 is a coefficient resulting from the difference between the molecular weights of the chitin and chitosan monomer units.

\subsubsection{TGA Measurement}

Weight measurements were performed using a 403 Aëolos Quadro quadrupole mass spectrometer from Nezsch. The samples were warmed from $40{ }^{\circ} \mathrm{C}$ to $650{ }^{\circ} \mathrm{C}$ at a heating rate of $20^{\circ} \mathrm{C} \mathrm{min}^{-1}$, and then the temperature was held at $650^{\circ} \mathrm{C}$ for a period of $4 \mathrm{~h}$.

\section{Results}

\subsection{Chitin and Chitosan Preparation}

Chitin extraction and chitosan preparation can be carried out following various methods based in either chemical or enzymatic strategies [50-53]. If the enzymatic strategy can be reported as a green way to produce chitosan, the chemical strategy is well established and allows production of chitosan with a high deacetylation degree. In this work, we employ a simple chemical strategy used for chitin and chitosan extraction [54]. In our strategy, we extract chitin in three straight-forward steps: (1) demineralization, (2) deproteination and (3) bleaching. Following the three-step chitin extraction, chitosan can then be obtained using a one-step strategy. As stated, chitin extraction begins with demineralization, which is achieved by immerging dry insect specimens in a $1 \mathrm{M} \mathrm{HCl}$ solution. The mixture is then warmed at $95^{\circ} \mathrm{C}$ for $2 \mathrm{~h}$, after which the liquid phase is removed, and the demineralized insect cuticle is thoroughly washed with water until achieving a neutral $\mathrm{pH}$. The resultant material was directly used for the next step, deproteination, without drying. For deproteination, the material was immersed in $2 \mathrm{M} \mathrm{NaOH}$ solution at $95^{\circ} \mathrm{C}$ for $36 \mathrm{~h}$. The $\mathrm{NaOH}$ solution turned black rapidly and was therefore refreshed regularly (every hour) until the solution stopped changing colour. After a 36-hour period, the liquid phase was removed and the solid was thoroughly washed with water until reaching a neutral $\mathrm{pH}$. The bleaching step was performed to remove any coloration of the chitin, using hydrogen peroxide $(50 \% \mathrm{w} / \mathrm{w})$ and washing with acetone to remove any potential residual trace fat. The final isolated solid is described as chitin (Figure 2A). 
A

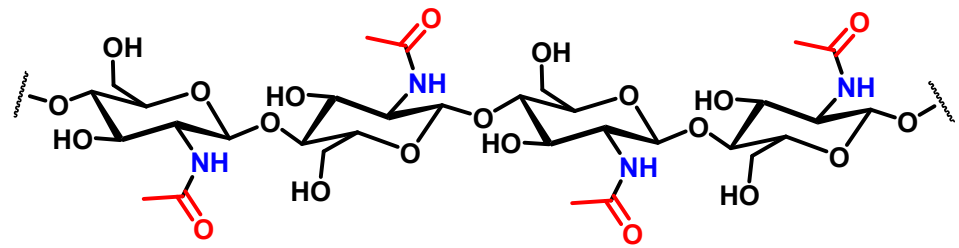

Chitin

B

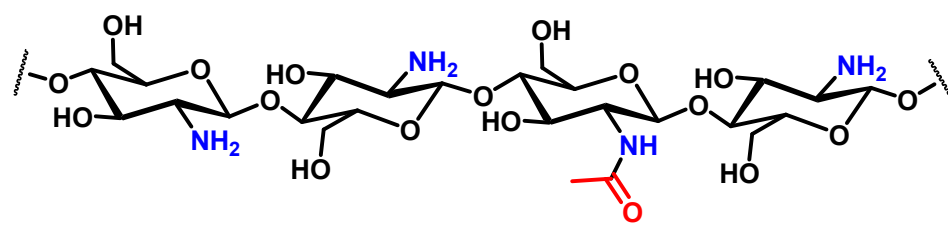

Chitosan

C

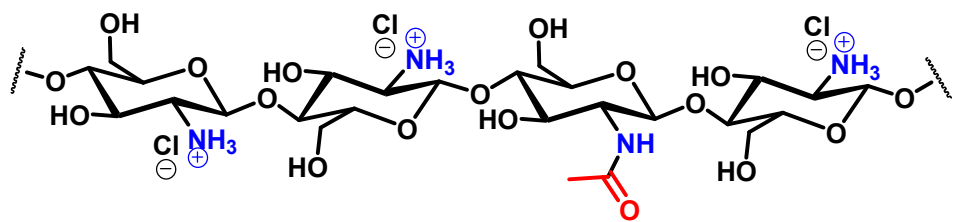

\section{Chitosan \\ hydrochloride}

Figure 2. Chemical structures of the formed molecules. (A) Chemical structure of chitin; (B) Chemical structure of chitosan; (C) Chemical structure of chitosan hydrochloride.

The final yield of isolated, dried chitin was $16 \%$, a value consistent with other reports in the literature [41]. Chitosan preparation from the extracted chitin was then performed in one step by immersing dried chitin in a 50/50 w/w aqueous $\mathrm{NaOH}$ solution and then heating the mixture to $95{ }^{\circ} \mathrm{C}$ overnight. After this period, the liquid was removed and the solid was thoroughly washed with water until reaching a neutral $\mathrm{pH}$. Finally, the solid was washed with acetone and dried (yield $80 \%$ ). The obtained compound was a poly ( $\beta-(1-4)$-D-glucosamine) with random presence of $\mathrm{N}$-acetyl-D-glucosamine, e.g. chitosan (Figure $2 \mathrm{~B}$ ). This compound was easily dissolved in a diluted $\mathrm{HCl}$ solution by forming the corresponding hydrochloride salt (Figure 2C).

\subsection{Macroscopic Observations}

During the chitin extraction, important macroscopic modifications were observed. Obviously, the demineralisation and the deproteination had a dramatic impact on the specimens. For example, most major parts of the specimens (elytra, pronotum etc.) detach during this process. However, other more subtle changes were observed, particularly with regards to colour.

G. orientalis is known as a black and white giant beetle, as shown in Figure 3A $[55,56]$. The appearance of the specimen did not change significantly after demineralisation; however, after deproteination, the G. orientalis appearance was modified dramatically to reveal an iridescent aspect. At this point, the majority of the body was maroon in color, with gold or intense green reflections depending on the observation angle (Figure 3B). This is not surprising, as iridescent colours are a common property of beetles $[57,58]$, and this iridescent effect is attributed to the chitin network. Therefore, it is not surprising that after deproteination and exposure of the chitin network, the iridescent properties are strongly evident. While it is well established that this metallic coloration can be removed from beetle by applying physical or chemical treatments, there are limited demonstrations that this class of optical properties can be exposed from species with non-metallic aspect [59-61]. After bleaching, the iridescent effect was preserved, demonstrating that bleaching does not disturb the chitin network; however, there was an associated colour change to a shiny pearl hue (Figure 3C). Unsurprisingly, after drying, the network changed dramatically, and no more iridescent colour could be observed (Figure 3D); this change in colour can probably be linked to the modification of the chitin network after drying. 


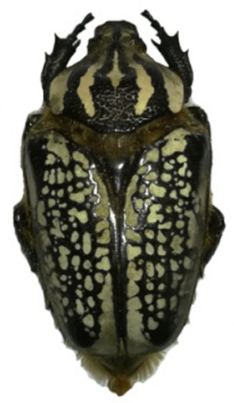

A

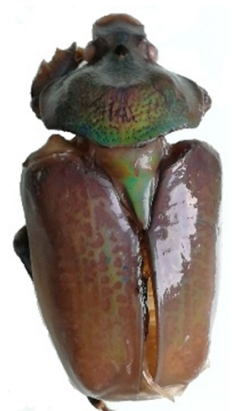

B

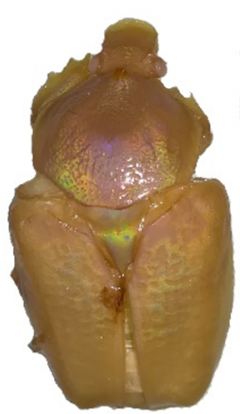

C

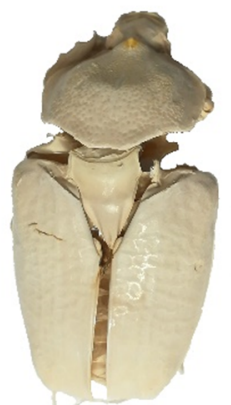

D

Figure 3. Example of G. orientalis morphological evolutions. (A) Starting specimen; (B) Specimen after deproteination; (C) Specimen after bleaching; (D) Specimen after drying.

\subsection{Microscopic Observations of G. orientalis Surface}

If macroscopic variations in the specimen evolve during chitin extraction, it is reasonable to consider the possibility that there are also microscopic changes. For this reason, each stage of chitin extraction and chitosan preparation was observed using scanning electronic microscopy (SEM). The native surface morphology of G. orientalis has been previously described in the literature [47] and it was revealed that the white domains of the shell have large fibre-like elements (Figure 4A) and the black sections are relatively smooth (Figure 4B).

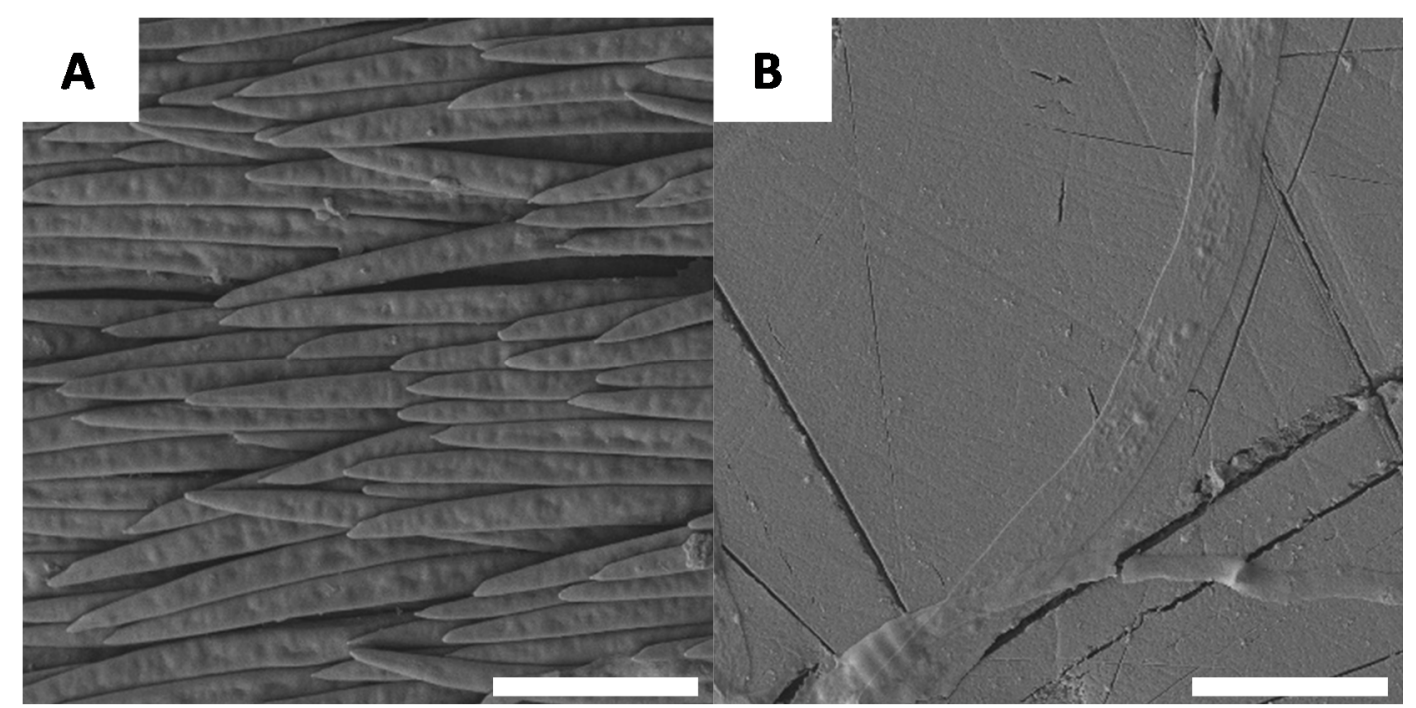

Figure 4. Example of native surfaces for G. orientalis, white $(\mathbf{A})$ and black $(\mathbf{B})$ part (Scale bar $=10 \mu \mathrm{m})$.

However, after demineralisation, we observed here that the white regions had an increasingly disordered morphology (Figure 5A), while the black domains remain, still, relatively smooth (Figure 5B). These results are consistent with the previously described macroscopic observations (Figure 3), as the general macroscopic morphologies and surface patterns are not significantly altered after demineralisation. 


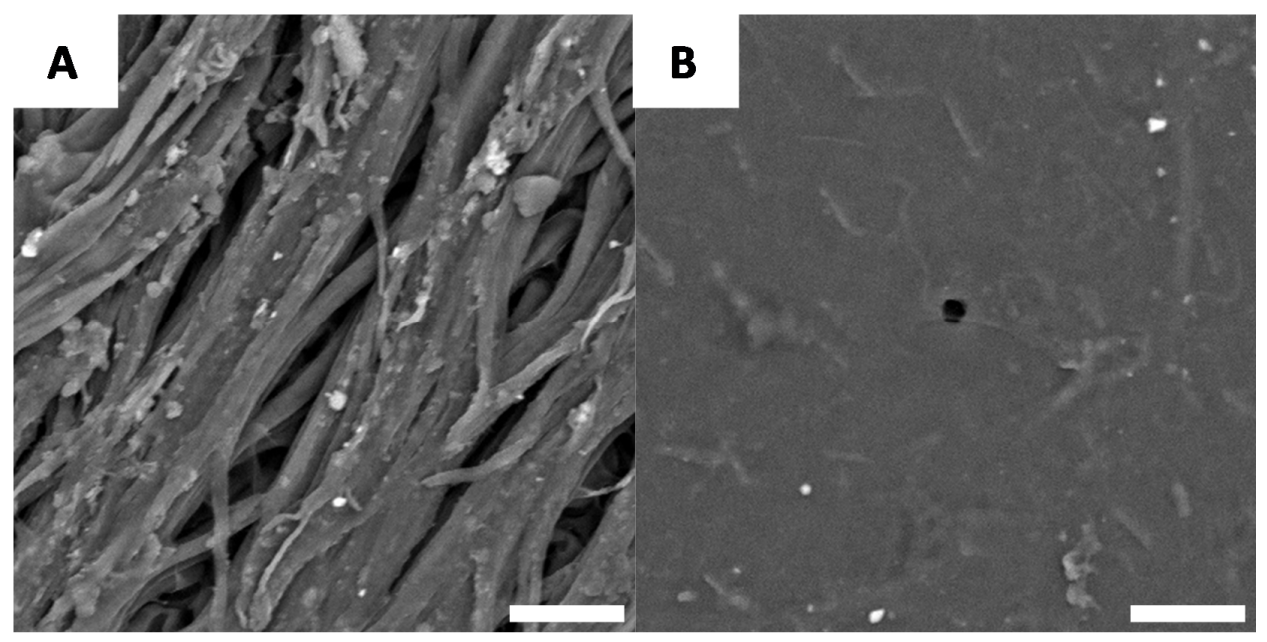

Figure 5. Example of surface morphology after demineralisation, for white (A) and black (B) part $($ Scale bar $=10 \mu \mathrm{m})$.

After deproteination, the black and white sections of the shell no longer have distinguishable microscopic morphologies. While there are a few regions of the surface that can be characterized as having irregular morphology (Figure 6A), the majority of the surface is characterized by a well-defined chitin network, as shown Figure 6B.

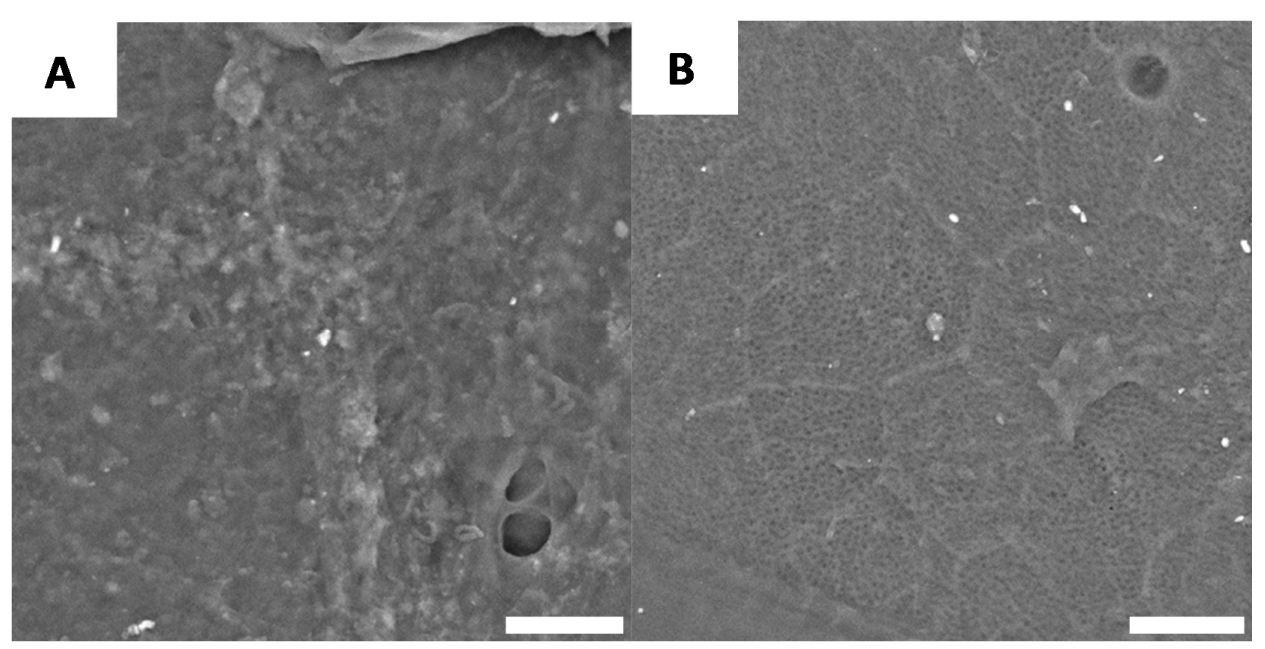

Figure 6. Examples of morphology observed for G. orientalis after deproteination (Scale bar $=10 \mu \mathrm{m}$ ).

(A) Example of observed irregular morphology; (B) Example of chitin network.

Microscopic observations made after bleaching yield similar results to Figure 6, further confirming the macroscopic observations. After bleaching, very few sections of the surface have minimal roughness (Figure 7A), while the majority of the surface again yields the chitin network. This network likely contributes to the iridescent effect observed on the macroscopic scale (Figure 7). Furthermore, with cross-section microscopy, it is possible to observe the layer-by-layer structure of the surface (Figure 7C,D).

After deacetylation, the entire surface is covered by a well-defined network (Figure 8A,B); after deproteination and bleaching, the layer-by-layer structure of the chitin is preserved and can be observed using cross-section microscopy (Figure 8C,D). 


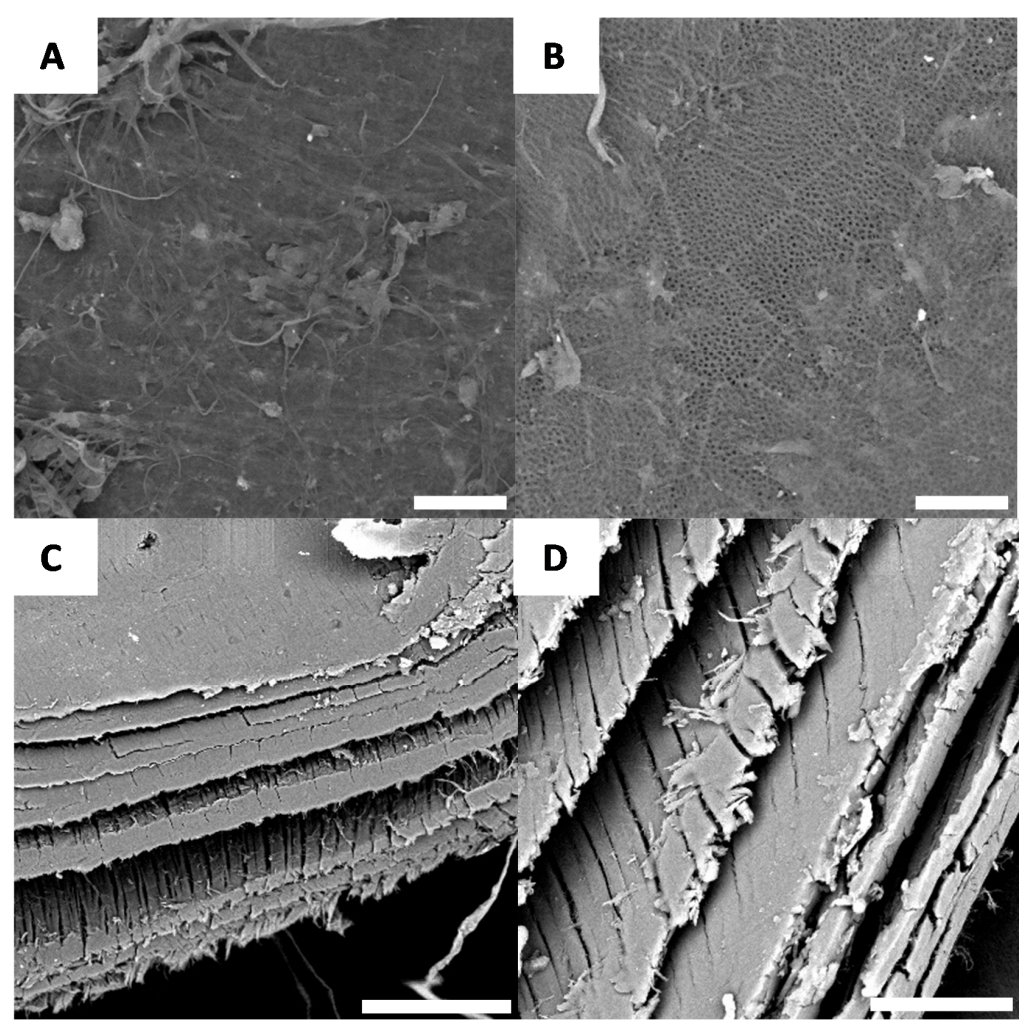

Figure 7. Examples of morphology observed for G. orientalis after bleaching (A and $\mathbf{B})$ (Scale bar = $10 \mu \mathrm{m})$; Cross-section observations for G. orientalis after bleaching (C and D) (Scale bar $=80 \mu \mathrm{m})$.

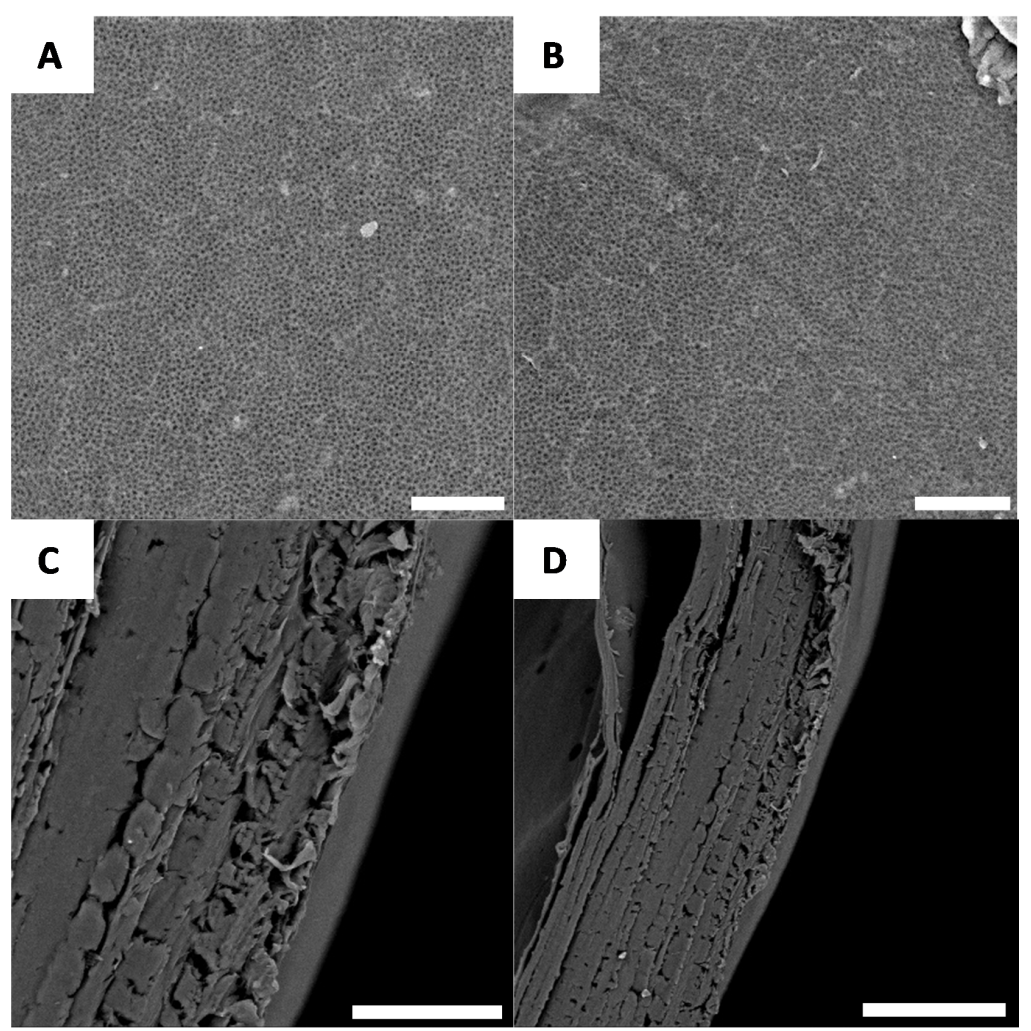

Figure 8. Examples of morphology observed for G. orientalis chitosan (A and B) (Scale bar $=10 \mu \mathrm{m})$; Cross-section observations for G. orientalis chitosan (C and D) (Scale bar $=80 \mu \mathrm{m})$. 


\subsection{G. orientalis Chitosan Characterisations}

To confirm the formation of chitosan, material characterisations such as infrared spectroscopy were employed (Figure 9).

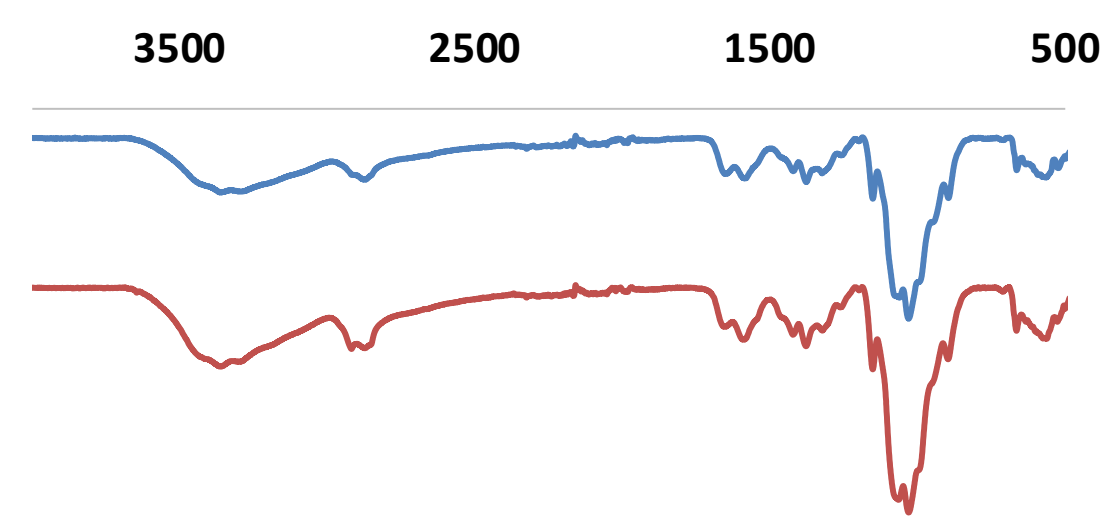

\section{-Shrimp - Beetle}

Figure 9. Infrared measurements for chitosan from shrimp (blue) and G. orientalis (red).

In the FT-IR spectra, all characteristic bands from chitosan are observed. This includes strong bands at $3340-3380 \mathrm{~cm}^{-1}$ and $3280-3293 \mathrm{~cm}^{-1}$, attributed to stretching of O-H and N-H groups, respectively. Furthermore, the band at $2846-2886 \mathrm{~cm}^{-1}$ is attributed to $\mathrm{CH}_{2}$ vibration. Not surprisingly, the $\mathrm{C}=\mathrm{O}$ band of the amide group is weak but can be observed at $1642-1660 \mathrm{~cm}^{-1}$, consistent with the partial deacetylation of chitin. Lastly, the bending band vibration band from N-H is observed at $1577-1588 \mathrm{~cm}^{-1}$. Compared to FT-IR spectra obtained from shrimp chitosan, no significant difference is noted.

The deacetylation degree was estimated using a titration method $[48,49]$. In this method, chitosan is dissolved in a $\mathrm{HCl}(1 \mathrm{M})$ solution. In this condition, all free amino groups form an ammonium chloride and any excess $\mathrm{HCl}$ remains in solution. The $\mathrm{HCl} /$ chitosan ammonium chloride solution is then titrated using $\mathrm{NaOH}(1 \mathrm{M})$. The titration curve shows two deflections. The first one corresponds to $\mathrm{HCl}$ and the second one to chitosan hydrochloride (Figure 10).
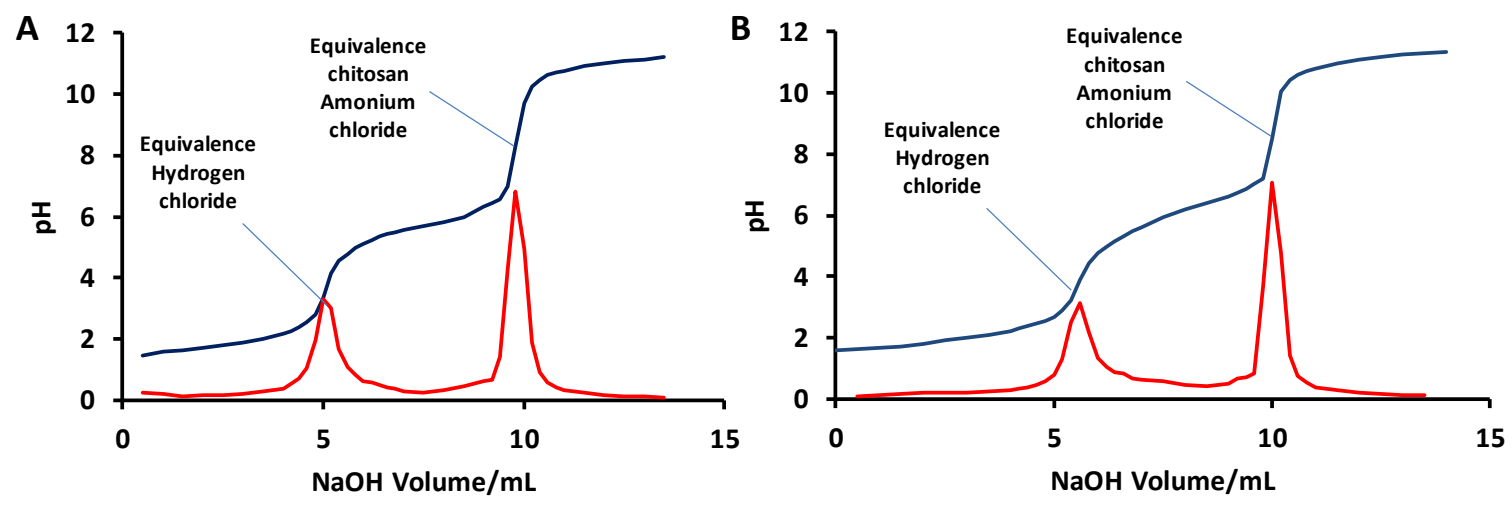

Figure 10. Example of titration curve for G. orientalis (A) and shrimp (B) chitosan deacetylation degree determination.

Using this approach, the deacetylation degree was determined to be $78.3 \pm 1.5 \%$ for G. orientalis. A similar calculation was performed for the shrimp chitosan, indicating $74.8 \pm 0.4 \%$ deacetylation. 
Both of these results are consistent with data published in the literature for shrimp or for various beetles [39].

Ash content is another important parameter used to evaluate chitosan quality. Ash content dramatically changes the viscosity and viscoelastic behaviour of materials formed from chitosan. For example, to form hydrogels, the ash content should be as low as possible (below 5\%). The ash content of G. orientalis was investigated using thermogravimetric analysis (Figure 11).

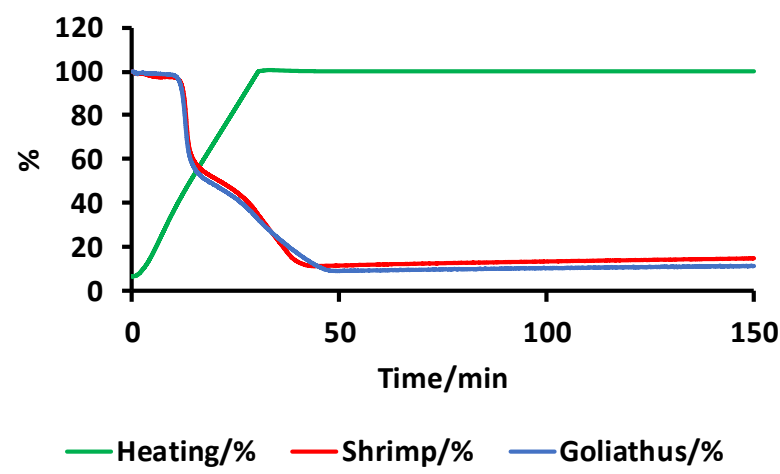

Figure 11. Thermogravimetric measurements for chitosan from G. orientalis (blue) and shrimp (red).

Thermogravimetric analysis reveals that chitosan from G. orientalis has an ash content of $9.1 \%$, which, compared to the ash content for shrimp chitosan (11.3\%), is relatively similar. The isolated chitosan in this study already presents a low ash content but should be purified for further applications.

\section{Conclusions}

In conclusion, we report the use of G. orientalis for the preparation of chitin and chitosan using a chemical treatment. After a multi-step process including demineralisation and deproteination, the chitin is obtained from G. orientalis with a yield of $16 \%$. This extraction procedure for chitin reveals the hidden macroscopic optical effect of G. orientalis. Furthermore, SEM observations reveal the microscopic evolution of the surface morphology with the extraction of the chitin network, which reveals an organized surface with limited rough, disordered domains. Chitosan is obtained after a deacetylation step of the chitin, with a yield of $80 \%$, a deacetylation degree of $78.3 \%$ and $9.1 \%$ ash content. Deacetylation degree and ash content are similar for our G. orientalis chitosan and commercially available shrimp chitosan. Furthermore, the G. orientalis chitosan has very similar properties compared with commercially available shrimp chitosan, as revealed by infrared spectroscopy. As a first observation, this work shows the possibility to extract chitin and chitosan from large-bodied beetles. In the future, various other large-bodied specimens from other species and genera should be investigated. Additionally, the prepared chitosan produced here will be investigated further for hydrogel elaboration, and the physicochemical properties of these gels will be investigated. The main final objective of this work will be to consider beetle chitosan for applications in 3D printing or biomedical applications.

Author Contributions: G.G. conceived and designed the experiments; G.G. and P.F. performed the experiments; G.G., R.-P.G. and C.R.S. analyzed the data; G.G. contributed reagents/materials/analysis tools; G.G., R.-P.G. and C.R.S. wrote the paper. All authors have read and agreed to the published version of the manuscript.

Acknowledgments: This work was supported by the French National Research Agency (ANR, Agence Nationale de la Recherche) as future investment project UCA ${ }^{\mathrm{JEDI}}$ with reference: No. ANR-15-IDEX-01. TGA and SEM measurements were performed at the Smart City Innovation Center (Université Côte d'Azur, IMREDD). The “Smart City Innovation Center" is a project funded by the European union with the European fund for regional development and co-funded by metropole Nice Côte d'Azur, the département Alpes-maritimes, the région Sud Provence-Alpes-Côte and France for the "initiative d'excellence" (Investissements d'avenir).

Conflicts of Interest: The authors declare no conflicts of interest. 


\section{References}

1. Hamed, I.; Ozogul, F.; Regenstein, J.M. Industrial applications of crustacean by-products (chitin, chitosan, and chitooligosaccharides): A review. Trends Food Sci. Technol. 2016, 48, 40-50. [CrossRef]

2. Martin, A. Fisheries waste biomass: Bioconversion alternatives. In Bioconversion of Waste Materials to Industrial Products; Springer: New York, NY, USA, 1998; pp. 449-479.

3. Simpson, B.K.; Gagne, N.; Simpson, M.V. Bioprocessing of chitin and chitosan. In Fisheries Processing; Springer: Boston, MA, USA, 1994; pp. 155-173.

4. Muzzarelli, R.A. Native, Industrial and fossil chitins. In Chitin and Chitinases; Birkhäuser Verlag AG: Basel, Switzerland, 1999; pp. 1-6.

5. Jones, M.; Kujundzic, M.; John, S.; Bismarck, A. Crab vs. Mushroom: A Review of Crustacean and Fungal Chitin in Wound Treatment. Mar. Drugs 2020, 18, 64. [CrossRef]

6. Khoushab, F.; Yamabhai, M. Chitin research revisited. Mar. Drugs 2010, 8, 1988-2012. [CrossRef] [PubMed]

7. Sikorski, P.; Hori, R.; Wada, M. Revisit of $\alpha$-Chitin Crystal Structure Using High Resolution X-ray Diffraction Data. Biomacromolecules 2009, 10, 1100-1105. [CrossRef] [PubMed]

8. Tolaimate, A.; Desbrieres, J.; Rhazi, M.; Algui, A. Contribution to the preparation of chitins and chitosans with controlled physico-chemical properties. Polymer 2003, 44, 7939-7952. [CrossRef]

9. Sahariah, P.; Másson, M. Antimicrobial Chitosan and Chitosan Derivatives: A Review of the StructureActivity Relationship. Biomacromolecules 2017, 18, 3846-3868. [CrossRef]

10. Yi, H.; Wu, L.-Q.; Bentley, W.E.; Ghodssi, R.; Rubloff, G.W.; Culver, J.N.; Payne, G.F. Biofabrication with Chitosan. Biomacromolecules 2005, 6, 2882-2894. [CrossRef]

11. Van Vlierberghe, S.; Dubruel, P.; Schacht, E. Biopolymer-Based Hydrogels as Scaffolds for Tissue Engineering Applications: A Review. Biomacromolecules 2011, 12, 1387-1408. [CrossRef]

12. Wang, H.; Qian, J.; Ding, F. Emerging Chitosan-Based Films for Food Packaging Applications. J. Agric. Food Chem. 2018, 66, 395-413. [CrossRef]

13. Shahid, M.; Mohammad, F. Green Chemistry Approaches to Develop Antimicrobial Textiles Based on Sustainable Biopolymers: A Review. Ind. Eng. Chem. Res. 2013, 52, 5245-5260. [CrossRef]

14. Thakur, V.K.; Thakur, M.K. Recent Advances in Graft Copolymerization and Applications of Chitosan: A Review. ACS Sustain. Chem. Eng. 2014, 2, 2637-2652. [CrossRef]

15. Uranga, J.; Etxabide, A.; Cabezudo, S.; De la Caba, K.; Guerrero, P. Valorization of marine-derived biowaste to develop chitin/fish gelatin products as bioactive carriers and moisture scavengers. Sci. Total Environ. 2020, 706, 135747. [CrossRef] [PubMed]

16. Negm, N.A.; Hefni, H.H.H.; Abd-Elaal, A.A.A.; Badr, E.A.; Abou Kana, M.T.H. Advancement on modification of chitosan biopolymer and its potential applications. Int. J. Biol. Micromol. 2020, 152, 681-702. [CrossRef]

17. Badhe, R.V.; Biju kumar, D.; Chejara, D.R.; Mabrouk, M.; Choonara, Y.E.; Kumar, P.; Du Toit, L.C.; Kondiah, P.P.D.; Pillay, V. A composite chitosan-gelatin bi-layered, biomimetic macroporous scaffold for blood vessel tissue engineering. Carbohydr. Polym. 2017, 157, 1215-1225. [CrossRef] [PubMed]

18. Xiaoying, K.; Jun, F.; Kai, S.; Lili, W.; Xuefang, L.; Jinsheng, S. Biomimetic hydrogel for rapid and scar-free healing of skin wounds inspired by the healing process of oral mucosa. Acta Biomater. 2019, 100, 255-269.

19. Zou, L.; Zhang, Y.; Liu, X.; Chen, J.; Zhang, Q. Biomimetic mineralization on natural and synthetic polymers to prepare hybrid scaffolds for bone tissue engineering. Colloids Surf. B Biointerfaces 2019, 178, $222-229$. [CrossRef] [PubMed]

20. Ghaeea, A.; Bagheri-Khoulenjanib, S.; Amir Afshara, H.; Bogheiria, H. Biomimetic nanocomposite scaffolds based on surface modified PCL-nanofibers containing curcumin embedded in chitosan/gelatin for skin regeneration. Compos. Part B Eng. 2019, 177, 107339. [CrossRef]

21. Cao, G.; Wang, C.; Fan, Y.; Li, X. Biomimetic SIS-based biocomposites with improved biodegradability, antibacterial activity and angiogenesis for abdominal wall repair. Mater. Sci. Eng. C 2020, 109, 110538. [CrossRef]

22. Yan, L.-P.; Wang, Y.-J.; Ren, L.; Wu, G.; Caridade, S.G.; Fan, J.-B.; Wang, L.-Y.; Ji, P.-H.; Oliveira, J.-M.; Oliveira, J.T.; et al. Genipin-cross-linked collagen/chitosan biomimetic scaffolds for articular cartilage tissue engineering applications. J. Biomed. Mater. Res. A 2010, 95, 465-475. [CrossRef]

23. Lua, D.; Wanga, H.; Wanga, X.; Lia, Y.; Guob, H.; Sunc, S.; Zhaoa, X.; Yanga, Z.; Leia, Z. Biomimetic chitosangraft-polypeptides for improved adhesion in tissue and metal. Carbohydr. Polym. 2019, 215, 20-28. [CrossRef] 
24. Kumar Mahanta, A.; Maiti, P. Injectable Hydrogel through Hydrophobic Grafting on Chitosan for Controlled Drug Delivery. ACS Appl. Bio Mater. 2019, 2, 5415-5426. [CrossRef]

25. Kumar Sharma, P.; Halder, M.; Srivastava, U.; Singh, Y. Antibacterial PEG-Chitosan Hydrogels for Controlled Antibiotic/ Protein Delivery. ACS Appl. Bio Mater. 2019, 2, 5313-5322. [CrossRef]

26. Nguyen Van Long, N.; Joly, C.; Dantigny, P. Active packaging with antifungal activities. Int. J. Food Microbiol. 2016, 220, 73-90. [CrossRef] [PubMed]

27. Verlee, A.; Mincke, S.; Stevens, C.V. Recent developments in antibacterial and antifungal chitosan and its derivatives. Carbohydr. Polym. 2017, 164, 268-283. [CrossRef] [PubMed]

28. Dutta, P.K.; Tripathi, S.; Mehrotra, G.K.; Dutta, J. Perspectives for chitosan based antimicrobial films in food applications. Food Chem. 2009, 114, 1173-1182. [CrossRef]

29. Zemskova, L.; Egorin, A.; Tokar, E.; Ivanov, V.; Bratskaya, S. New Chitosan/Iron Oxide Composites: Fabrication and Application for Removal of $\mathrm{Sr}^{2+}$ Radionuclide from Aqueous Solutions. Biomimetics 2018, 3, 39. [CrossRef] [PubMed]

30. Chtchigrovsky, M.; Primo, A.; Gonzalez, P.; Molvinger, K.; Robitzer, M.; Quignard, F.; Taran, F. Functionalized Chitosan as a Green, Recyclable, Biopolymer-Supported Catalyst for the [3 + 2] Huisgen Cycloaddition. Angew. Chem. Int. Ed. 2009, 48, 5916-5920. [CrossRef]

31. Khalil, K.; Al-Matar, H.; Elnagdi, M. Chitosan as an EcoFriendly Heterogeneous Catalyst for Michael Type Addition Reactions. A Simple and Efficient Route to Pyridones and Phthalazines. Eur. J. Chem. 2010, 1, 252-258. [CrossRef]

32. Marei, N.H.; Abd El-Samie, E.; Salah, T.; Saad, G.R.; Elwahy, A.H.M. Isolation and characterization of chitosan from different local insects in Egypt. Int. J. Biol. Macromol. 2016, 82, 871-877. [CrossRef]

33. Ifuku, S.; Nomura, R.; Morimoto, M.; Saimoto, H. Preparation of Chitin Nanofibers from Mushrooms. Materials 2011, 4, 1417-1425. [CrossRef]

34. Vetter, J. Chitin content of cultivated mushrooms Agaricus bisporus, Pleurotus ostreatus and Lentinula edodes. Food Chem. 2007, 102, 6-9. [CrossRef]

35. Juárez-de la Rosa, B.A.; Quintana, P.; Ardisson, P.-L.; Yáñez-Limón, J.M.; Alvarado-Gil, J.J. Effects of thermal treatments on the structure of two black coral species chitinous exoskeleton. J. Mater. Sci. 2012, 47, 990-998. [CrossRef]

36. Kaya, M.; Baran, T.; Mentes, A.; Asaroglu, M.; Sezen, G.; Tozak, K.Ö. Extraction and Characterization of $\alpha$-Chitin and Chitosan from Six Different Aquatic Invertebrates. Food Biophys. 2014, 9, 145-157. [CrossRef]

37. Kaya, M.; Erdogan, S.; Molb, A.; Baran, T. Comparison of chitin structures isolated, from seven orthoptera species. Int. J. Biol. Macromol. 2015, 72, 797-805. [CrossRef]

38. Kaya, M.; Baran, T. Description of a new surface morphology for chitin extracted from wings of cockroach (Periplaneta americana). Int. J. Biol. Macromol. 2015, 75, 7-12. [CrossRef]

39. Shina, C.-S.; Kimb, D.-Y.; Shina, W.-S. Characterization of chitosan extracted from Mealworm Beetle (Tenebrio molitor, Zophobas morio) and Rhinoceros Beetle (Allomyrina dichotoma) and their antibacterial activities. Int. J. Biol. Macromol. 2019, 125, 72-77. [CrossRef]

40. Kaya, M.; Bulut, E.; Mujtaba, M.; Sivickis, K.; Sargin, I.; Akyuz, B.; Erdogan, S. Gender influences differentiation of chitin among body parts. Arch. Insect Biochem. Physiol. 2016, 93, 96-109. [CrossRef]

41. Kabalaka, M.; Aracagöka, D.; Torunb, M. Extraction, characterization and comparison of chitins from large bodied four Coleoptera and Orthoptera species. Int. J. Biol. Macromol. 2020, 145, 402-409. [CrossRef]

42. Orsi, L.; Voege, L.L.; Stranieri, S. Eating edible insects as sustainable food? Exploring the determinants of consumer acceptance in Germany. Food Res. Int. 2019, 125, 108573. [CrossRef]

43. Fiebelkorn, F.; Kuckuck, M. More and more people hungry for meat. Insects as a sustainable meat substitute of the future? Geogr. Rundsch. 2019, 71, 48-51.

44. Oonincx, D.G.A.B.; Van Itterbeeck, J.; Heetkamp, M.J.W.; Van den Brand, H.; Van Loon, J.J.A.; Van Huis, A. An Exploration on Greenhouse Gas and Ammonia Production by Insect Species Suitable for Animal or Human Consumption. PLoS ONE 2010, 5, e14445. [CrossRef] [PubMed]

45. Godeau, G.; Orange, F.; Godeau, R.-P.; Szczepanski, C.R.; Guittard, F.; Darmanin, T. Variations in Surface Structures and Wettability in the Genus Pachnoda Burmeister. Bioinspired Biomimetic Nanobiomater. 2019, 8 , 181-189. [CrossRef] 
46. Montreuil, O.; Candet, C.; Bonaccorso, A.; Szczepanski, C.R.; Orange, F.; Godeau, R.-P.; Guittard, F.; Darmanin, T.; Godeau, G. Micro- and nanoscopic observations of sexual dimorphisms in Mecynorhina polyphemus confluens (Kraatz, 1890) (Coleoptera, Cetoniidae, Goliathini) and consequences for surface wettability. Arthropod Struct. Dev. 2019, 49, 10-18. [CrossRef] [PubMed]

47. Godeau, G.; Godeau, R.-P.; Orange, F.; Szczepanski, C.R.; Guittard, F.; Darmanin, T. Variation of Goliathus orientalis (moser, 1909) elytra nanostructurations and their impact on wettability. Biomimetics 2018, 3, 6. [CrossRef] [PubMed]

48. Czechowska-Biskup, R.; Jarosińska, D.; Rokita, B.; Ulański, P.; Rosiak, J.M. Determination of degree of deacetylation of chitosan-Comparision of methods. Prog. Chem. Appl. Chitin Deriv. 2012, 12, 5-20.

49. Liu, Y.; Xing, R.; Yang, H.; Liu, S.; Qin, Y.; Li, K.; Yu, H.; Li, P. Chitin extraction from shrimp (Litopenaeus vannamei) shells by successive two-step fermentation with Lactobacillus rhamnoides and Bacillus amyloliquefaciens. Int. J. Biol. Micromol. 2020, 148, 424-433. [CrossRef] [PubMed]

50. Tan, Y.N.; Lee, P.P.; Chen, W.N. Microbial extraction of chitin from seafood waste using sugars derived from fruit waste-stream. AMB Express 2020, 10, 17. [CrossRef]

51. Soon, C.Y.; Tee, Y.B.; Tan, C.H.; Rosnita, A.T.; Khalina, A. Extraction and physicochemical characterization of chitin and chitosan from Zophobas morio larvae in varying sodium hydroxide concentration. Int. J. Biol. Micromol. 2018, 108, 135-142. [CrossRef]

52. Muzzarelli, R.A.A. Chitin; Pergamon Press: Oxford, UK, 1977; p. 105.

53. Younes, I.; Hajji, S.; Frachet, V.; Rinaudo, M.; Jellouli, K.; Nasri, M. Chitin extraction from shrimp shell using enzymatic treatment. Antitumor, antioxidant and antimicrobial activities of chitosan. Int. J. Biol. Macromol. 2014, 69, 489-498. [CrossRef]

54. Younes, I.; Hajji, S.; Frachet, V.; Rinaudo, M.; Jellouli, K.; Nasri, M. Preparation and characterization of $\alpha$-chitin from cicada sloughs. Mat. Sci. Eng. C 2010, 30, 357-363.

55. Lachaume, G. Les Coléoptères du Monde 3. In Goliathini 1: Goliathus, Argyrophegges, Fornasinius, Hegemus; Sciences Nat: Venette, France, 1983; pp. 1-113.

56. Mawdsley, J.R. Taxonomy of the Goliath beetle Goliathus orientalis Moser, (Coleoptera: Scarabaeidae: Cetoniinae). J. Nat. Hist. 2013, 47, 1451-1461. [CrossRef]

57. Seago, A.E.; Brady, P.; Vigneron, J.-P.; Schultz, T.D. Gold bugs and beyond: A review of iridescence and structural colour mechanism in beetles (coleoptera). J. R. Soc. Interface 2009, 6, S165-S184. [CrossRef] [PubMed]

58. Burg, S.L.; Parnell, A.J. Self-assembling structural colour in nature (Topical Review). J. Phys. Condens. Matter. 2018, 30, 413001. [CrossRef] [PubMed]

59. Mason, C.W. Structural colour in insects. I. J. Phys. Chem. 1926, 30, 383-395. [CrossRef]

60. Mason, C.W. Structural colour in insects. II. J. Phys. Chem. 1927, 31, 321-354. [CrossRef]

61. Mason, C.W. Structural colour in insects. III. J. Phys. Chem. 1927, 31, 1856-1872. [CrossRef] 